\title{
Need For Advanced Facilities and Equipments in Physical Education Colleges
}

\author{
Dr. Prof. T. F Gulhane \\ Rajiv Gandhi College of Engineering Research \& Technology, Chandrapur, \\ Maharashtra, India
}

\begin{abstract}
This paper mainly exposed the problems and of facilities and equipments in physical education colleges. The objective of this article is to study the problems for facilities and equipments available in physical education colleges and to focus on the goal for improving the quality of teaching and learning in physical education.

It also discussed the poor maintenance culture of facilities, and equipments. It presents the findings of an evaluation of physical Education [PE] colleges and makes recommendations for the further development of this subject. Based on the data analysis and discussion, it was concluded that improvisation is very necessary because of the growing number of enrolment of students, the reduced amount spent on facilities and equipment in PE colleges and Recruitments of qualified faculties.
\end{abstract}

Keywords: Physical Education, Facilities, Equipments, Qualified faculties.

\section{Introduction}

In India physical education colleges required a large variety of facilities and equipments for both internal external prudes. The relative needs of the students should be recognized in the planning of facilities, for their use and onto the purchase of equipments,

In order to achieve this objectives, the Government through NCTE laid norms for standard facilities and sports equipment to be made available for various courses in PE, but the task of NCE failed also the problems of facilities and equipment becomes a major issue of concern by many sports researchers of an area.

Various types of equipments and adequate facilities make teaching and learning more interesting and effective in various PE courses maintenance of adequate facilities, and equipments may often used to constitute a managerial problem. Recent studies and experimentations had yield a new trend for the re construction of physical education facilities. and equipments.

\section{Problems Of Facilities And Equipment Arise In Physical Education Colleges}

The effective performance in physical education involves the determination, allocation for the achievements which require data large amount of fund every year.

Also equipment such as balls, nets, javelin, rackets, hockey sticks, bats, gymnastic and athletic (track and field) materials, requires either purchasing, replacement or repairs either purchasing, replacement or repairs, Bucher and krotee (2002) thought that the facilities should be well planned and constructed with an eye in future. Often, facilities are constructed within a very short period of and are very difficult to expand or exchange.

According to pate et al. (1997) it might be impossible to achieve satisfactory results from students whose training facilities and equipment are inadequate or of sub-standard. It is also noted that most of the PE students lack exposure to modern sophisticated infrastructural facilities and equipments for training.

\section{Maintenance Of Facilities And Equipments In Physical Education Colleges}

Maintenance should be established by college administration with proper replacement of facilities and equipments PE. Bucher and Krotte (2002) though that the equipment and facilities should always be maintained. in a serviceable condition. Procedures for caring facilities and equipments should be reutilized. and all equipments should be checked and then repaired, replaced, or serviced as needed and stored properly. Facilities and equipments should be very attractive and esthetically pleasing and should be easy and economically maintained durably the planning construction, and use of facilities should consider the following aspects: (a) Validity, (b) Utility, (c) Accessibility, (d) Isolation, (e) Departmentalization, (f) Safety, (hygiene and sanitation) (g) Supervision, (h) Durability and Maintenance, (i) Beauty, (j) Flexibility and Expansibility, (k) Economy and (1) Acoustics. 


\section{Objectives \& Methodologies}

Bringing the objectives behind is to find out the need for improvisation in the field of facilities and equipments in sports and also create awareness in all teaching faculties. such as all PE colleges requires facilities in various courses as per the norms. Research design, the descriptive survey research design method was employed 27 PE colleges Dept's staff of affiliated to Sant Gadge Baba Amravati University, Amravati were purposively sampled. A structured, validated and reliable yes / no designed questionnaire was used for data collection. the data gathered were analyzed using frequency count $\&$ percentages.

\section{Analysis \& Interpretation Of Data}

All faculties had analyzed that students lack of motivation for learning in PE colleges due to lack of facilities and equipments. It is found that all PE institutions had failed to meet the because requirements regarding equipments and facilities sports fields.

As per NCTE the area of outdoor sports field per students is not clearly specified all the PE colleges \& still had a long way to meet the demand for international requirements. Expansion of Gyms and Addition of Equipment and Facilities. All PE colleges are lagging behind related expansion of Gyms and Addition of Equipment and Facilities required as per the number of students admitted.

Imbalance in PE teaching is due to lack of equipments and facilities in sports field is mainly brought lack and lagging equipments and facilities in sports field. All PE colleges surveyed that the average maintenance for funding is "Not enough "and no budgetary provisions are made nor planned. The majority of PE colleges think that the funds received from students are small and accepts that it had negative impacts on the operation of the PE teaching.

The major flaws in success for physical education colleges are sub- standard facilities, lack of sophisticated equipments, un availability of regular qualified teaching facilities are failed. Qualified Faculties, provide facilities and equipment, which are very important aspects required for well equipped and good playground for training.

\section{Conclusion}

This paper study the various aspects and problems arises in PE college which are manifested in various types, have complex forms and have brought negative influences on teaching which was deeply affected the pace of implementation of quality oriented education in these PE institutions. The factors resulting in each type of problems are neither simple nor isolated.

This problems was arises by many factors, and each factor may lead to many problems. Among these, the internal factors mainly include lack of professional ethics, low personal qualities and inferior teaching skills of the teachers. The external factors mainly includes rational teaching system and inadequate supervision on teaching. Therefore, the preventive measures were taken for these problems are not simple, but of various aspects involving the whole system of teaching.

\section{References}

[1]. Bucher A.C. \& Krotec, L. M. (2002) Management of Physical education and sports (12 ${ }^{\text {th }}$ Ed.) New York : Mc Graw Hill.

[2]. Bucher A.C. \& Irstee, M.C. (2002) Management of Physical Education Programmes Including Athlete. ( ${ }^{\text {th }}$ Ed.) St. Louis : The C.V. Mosby Company.

[3]. Crompton, J. L. (2005). Economic impact analysis of sports facilities and events: Eleven Sources of misapplication Journal of Sport Management.

[4]. Flynn, R. B. (1993). Planning facilities for athletics, Physical education and recreation. Reston. VA. AAHPERD.

[5]. Obiyemi, O.O. Adesoye. AA \& Ojo. S.S. (2006) Sport facilities and equipment management practice and provision in college of Education, Jalingo, Lorin Journal of Health physical Education \& Recreation.

[6]. Olajide O A. (2007) Introduction to sports management yola-Nigeria. Paraclete Publishers.

[7]. Pate, D.W. Moffit, E. \& Fugett, D. (1997) Current trend in use, design / construction. and finishing of sports facilities. Sports Marketing Quarterly, 2 (4): 9-14.

[8]. Pate, D.W. Moffit, E. \& Fugett, D. (1997) Current trend in use, design/ construction, and finishing of sports facilities. Sports Marketing Quarterly, 2 (4):9-14

[9]. Talabi, A. E. (1998) Poor facilities : A detergent to skill excellence in sports. Journal of Nigeria Academy of sport administration. 5 (1) $93-94$ 